\begin{tabular}{ll|l}
\cline { 2 - 3 } & \multicolumn{2}{l}{ Intervent Neurol 2014;3:122-128 } \\
\cline { 2 - 3 } & $\begin{array}{l}\text { DOI: 10.1159/000381035 2015 S. Karger AG, Basel } \\
\text { Published online: April 16, } 2015\end{array}$ & $\begin{array}{l}\text { 1664-9737/15/0034-0122\$39.50/0 } \\
\text { www.karger.com/ine }\end{array}$ \\
\hline
\end{tabular}

\title{
Spontaneous Thrombosis of a Ruptured Brain Arteriovenous Malformation: The Argument for Early Conservative Management
}

\author{
Nitin Goyal ${ }^{a} \quad$ Daniel Hoit ${ }^{b, c} \quad$ Lucas Elijovich $^{a-c}$ \\ Departments of a Neurology and ${ }^{b}$ Neurosurgery, University of Tennessee Health Sciences \\ Center, and 'Semmes-Murphey Neurologic and Spine Institute, Memphis, Tenn., USA
}

\section{Key Words}

Arteriovenous malformations $\cdot$ Intracranial hemorrhage $\cdot$ Arteriovenous malformation ruptures $\cdot$ Spontaneous thrombosis $\cdot$ Cerebrovascular hemorrhage

\begin{abstract}
Generally, definitive treatment of brain arteriovenous malformations (BAVM) presenting with hemorrhage is recommended to prevent recurrent hemorrhage. The risk of craniotomy and resection of BAVM has been well described using the Spetzler-Martin grading scale; however, the optimal timing for the definitive treatment of ruptured BAVM remains unclear. We report an interesting case of spontaneous BAVM thrombosis in which the patient presented with right occipital intracerebral hemorrhage caused by ruptured right occipital micro-BAVM. A preoperative angiogram 4 months later demonstrated spontaneous thrombosis of the AVM. Despite the risk of re-bleeding, the decision to defer treatment in the acute stage of illness in this case was based on the absence of high-risk angioarchitectural features in the arteriovenous malformations (AVM). It is important to emphasize the potential benefits of early conservative management, particularly in patients with low-risk angiographic features. We also review the literature of spontaneous BAVM thrombosis and discuss the potential benefit of early conservative management.

(C) 2015 S. Karger AG, Basel
\end{abstract}

\section{Introduction}

Brain arteriovenous malformations (BAVM) are abnormal connections of venous and arterial systems without intervening capillary network. They occur in $0.1 \%$ of the population [1], with the prevalence in adults being approximately 18/100,000. The usual age range of presentation is $10-40$ years, and the most common clinical presentation is intracranial hemor- 
rhage followed by seizure, headache, and focal neurological deficits. Clinical presentation varies with size, location, and other angioarchitectural features of arteriovenous malformations $(A V M)$, including the presence of intranidal aneurysms and venous outflow restriction [2].

Definitive treatment of BAVM presenting with hemorrhage is generally recommended to prevent recurrent hemorrhage. The risk of craniotomy and resection of BAVM has been well described using the Spetzler-Martin grading scale [3]; however, the optimal timing for the definitive treatment of ruptured BAVM remains unclear. Spontaneous angiographic regression has been seen in $<1.5 \%$ of all BAVM [4].

In this report, we present a case of a ruptured BAVM that was treated conservatively in the acute period and subsequently underwent spontaneous thrombosis. We reviewed the literature on BAVM spontaneous thrombosis and discuss the potential benefit of early conservative management.

\section{Case Report}

A 32-year-old African-American female with a medical history of non-insulin-dependent diabetes mellitus presented with sudden onset of headache and blurred vision. Home medications included metformin, aspirin, and oral contraceptives. Neurological examination demonstrated a left inferior quadrantanopsia. CT and MRI of the brain revealed a right occipital intracerebral hemorrhage (ICH). She was initially managed in the neurocritical care unit with supportive treatment and blood pressure control. Subsequent digital subtraction angiography demonstrated a right occipital micro-BAVM (Spetzler-Martin grade 2) with involvement of the eloquent visual cortex (fig. 1). The patient was discharged home with normalization of her visual field, with formal Goldman perimetry testing on clinic follow-up. Available treatment options were discussed with the patient. She returned 4 months later for planned angiography and resection of the AVM, but a repeat preoperative angiogram demonstrated spontaneous thrombosis of the AVM (fig. 2).

\section{Methods}

We conducted a PubMed search from 1955 to 2013 of cases with the following search terms: spontaneous regression; disappearance; thrombosis of brain AV malformation associated with intracerebral (ICH); subarachnoid (SAH), and intraventricular hemorrhage (IVH) (table 1). Data describing age, sex, presentation, location of AVM, number of arterial feeders, venous drainage outlets, and size of the nidus were obtained from the search results [4-28].

\section{Results}

In our review, 47 cases of spontaneous regression, disappearance, and/or thrombosis of a BAVM associated with rupture at presentation have been reported. Out of these 47 cases, $26(55.31 \%)$ included male patients and $21(44.68 \%)$ included female patients. The mean age was 38 with a range of 10-65 years. Thirteen patients presented with SAH, 21 patients presented with ICH, 9 patients presented with IVH, and 4 patients presented with multiple compartment hemorrhage (any combination of ICH, SAH, or IVH). The location of AVM hemorrhages were frontal lobe [8], parietal lobe [14], occipital lobe in 5, and cerebellar hemisphere in 4 patients. Twenty-five patients (59.5\%) had a single arterial feeder to AVM, while 18 patients had multiple arterial feeders (41.0\%). In 4 patients, arterial feeders were not reported. Thirty-two patients $(82.0 \%)$ were found to have single venous drainage from the AVM. In 8 patients, venous drainage was not reported. The size of the AVM nidus was $\leq 3 \mathrm{~cm}$ in 27 out of 31 patients (87.1\%) for whom the size of the nidus was given. Only 4 patients $(12.9 \%)$ were reported to have a nidus size of $>3 \mathrm{~cm}$. 

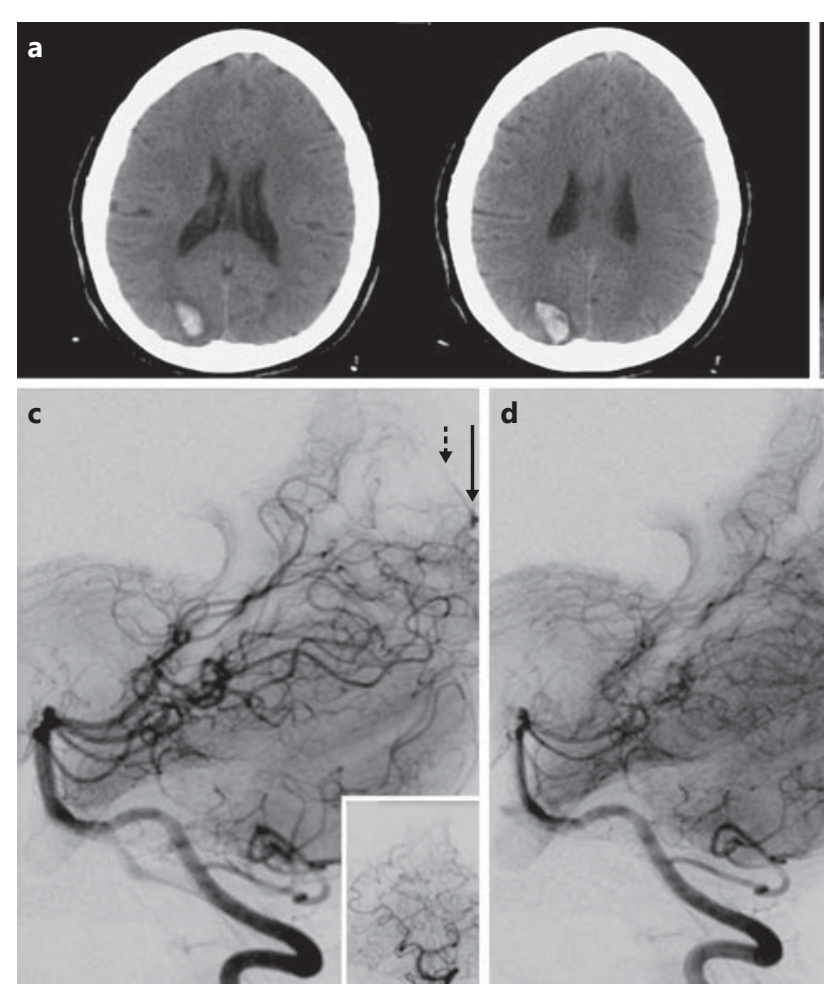
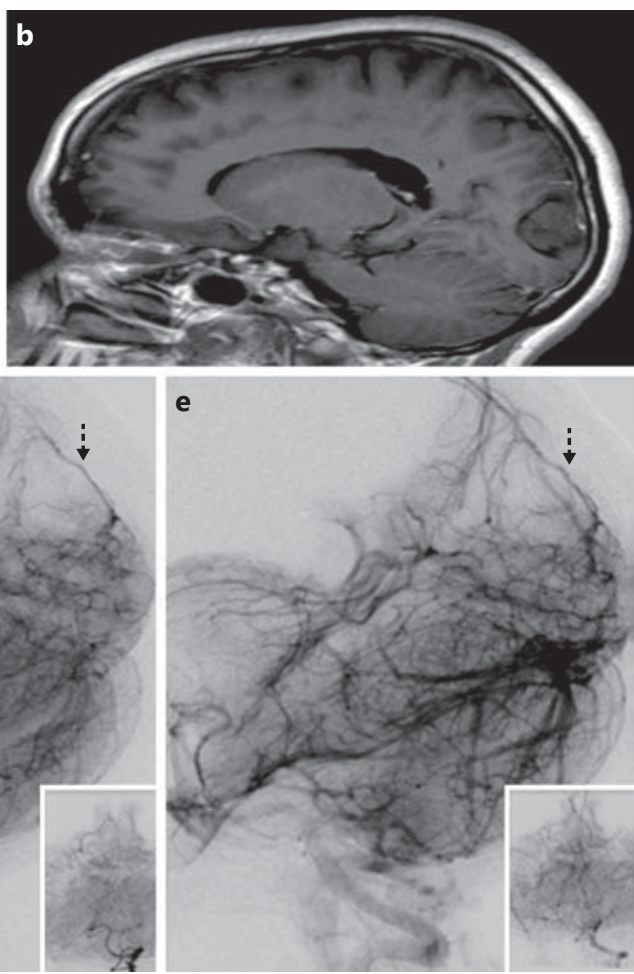

Fig. 1. a Head CT without contrast demonstrates a right occipital hemorrhage. b A sagittal T1-weighted brain MRI without contrast demonstrates an isodense hematoma in the right occipital lobe. A left vertebral digital subtraction angiogram lateral projection in the arterial (c), late arterial (d), and capillary phase (e) demonstrates a micro-AVM nidus (black arrow) fed by the cortical branch of the calcarine artery. The draining cortical vein (dashed arrows) is seen in the arterial phase with capillary filling defect, indicating the adjacent hematoma.
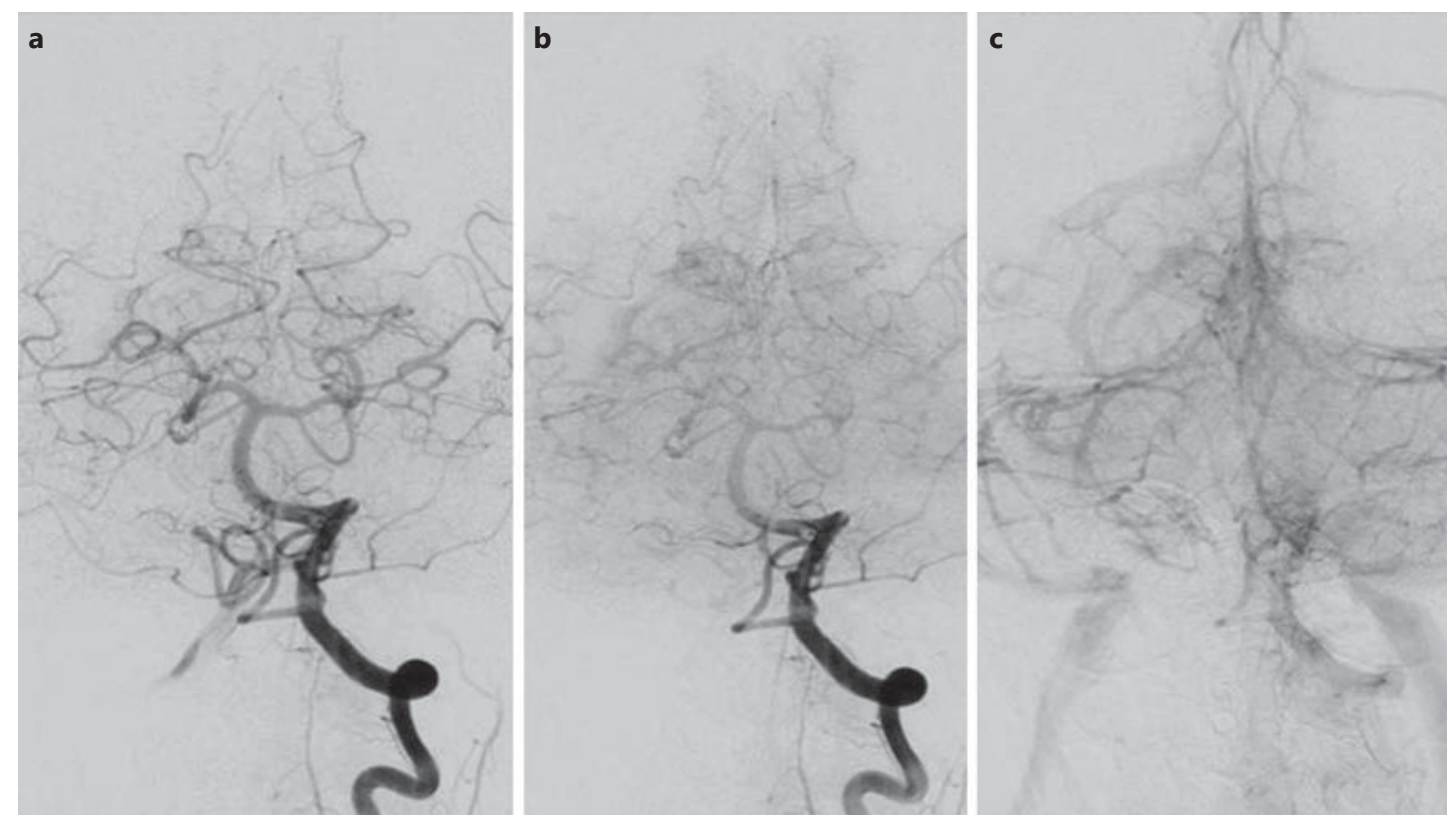

Fig. 2. Left vertebral artery digital subtraction angiography. Arterial (a), mid-arterial (b), and capillary (c) phase images demonstrate no evidence of arteriovenous shunting. 
Table 1. Results of BAVM case report literature search in PubMed

\begin{tabular}{|c|c|c|c|c|c|c|c|}
\hline $\begin{array}{l}\text { First author [ref.], } \\
\text { year }\end{array}$ & $\begin{array}{l}\text { Patient } \\
\text { age, } \\
\text { years }\end{array}$ & $\begin{array}{l}\text { Patient } \\
\text { gender }\end{array}$ & Presentation & Location of AVM & $\begin{array}{l}\text { Arterial } \\
\text { feeder(s) }\end{array}$ & $\begin{array}{l}\text { Venous } \\
\text { outflow(s) }\end{array}$ & $\begin{array}{l}\text { Size of } \\
\text { nidus, cm }\end{array}$ \\
\hline De Lange [5], 1955 & 64 & $\mathrm{~F}$ & SAH & occipital & single & single & 3.5 \\
\hline Kushner [6], 1970 & 53 & M & SAH & frontal & single & multiple & unreported \\
\hline Conforti [7], 1971 & 37 & $\mathrm{~F}$ & SAH & frontal & single & single & unreported \\
\hline Eisenman [8], 1972 & 34 & $\mathrm{~F}$ & SAH & parietal & unreported & single & unreported \\
\hline Levine [9], 1973 & 40 & M & $\mathrm{ICH}$ & parietal & single & unreported & unreported \\
\hline Heeres [10], 1976 & 34 & M & SAH & frontal & unreported & single & unreported \\
\hline Sasaki [11], 1976 & 57 & M & ICH & parietal & multiple & single & unreported \\
\hline Miyazaki [12], 1978 & 46 & M & SAH & parietal & single & multiple & 3.5 \\
\hline Sartor [13], 1978 & 24 & $\mathrm{~F}$ & ICH & basal ganglia & single & unreported & unreported \\
\hline \multirow[t]{2}{*}{ Nukui [14], 1982} & 54 & M & SAH & occipital & single & single & 1.4 \\
\hline & 26 & M & ICH & parietal & single & single & 7 \\
\hline Omojola [15], 1982 & 40 & $\mathrm{~F}$ & $\mathrm{ICH}$ & parietal & single & single & unreported \\
\hline Wakai [16], 1983 & 17 & M & SAH & frontal & multiple & multiple & 4 \\
\hline Pasqualin [17], 1985 & 16 & M & ICH & parietal & single & unreported & $<2$ \\
\hline Takano [18], 1987 & 65 & M & ICH & parietal & single & single & 2 \\
\hline Gibb [19], 1988 & 15 & $\mathrm{~F}$ & SAH & basal ganglia & multiple & multiple & unreported \\
\hline \multirow[t]{3}{*}{ Minakawa [20], 1989} & 34 & M & ICH & parietal & single & unreported & unreported \\
\hline & 32 & M & $\mathrm{ICH}$ & parietal & single & unreported & unreported \\
\hline & 32 & M & ICH & parietal & single & unreported & unreported \\
\hline Salpietro [21], 1989 & 35 & $\mathrm{~F}$ & SAH & parietal & single & single & unreported \\
\hline Barker [22], 1990 & 23 & $\mathrm{~F}$ & IVH & parietal & single & multiple & unreported \\
\hline Ezura [23], 1992 & 59 & M & ICH & occipital & multiple & multiple & unreported \\
\hline Mizutani [24], 1995 & 59 & M & SAH & frontal & multiple & single & unreported \\
\hline \multirow[t]{3}{*}{ Abdulrauf [4], 1999} & 28 & M & IVH & cerebellum & multiple & single & $<3$ \\
\hline & 35 & M & IVH & parietal & unreported & single & 3 \\
\hline & 37 & $\mathrm{~F}$ & $\mathrm{ICH}$ & thalamus & single & single & 2 \\
\hline \multirow[t]{16}{*}{ Patel [25], 2001} & 42 & $\mathrm{~F}$ & ICH/IVH/SAH & corpus callosum & single & single & $<1$ \\
\hline & 55 & $\mathrm{~F}$ & SAH & corpus callosum & single & single & 1.5 \\
\hline & 18 & $\mathrm{~F}$ & IVH & foramen of Monro & multiple & single & $<1$ \\
\hline & 44 & M & $\mathrm{ICH}$ & midbrain & multiple & single & $<1$ \\
\hline & 41 & M & $\mathrm{ICH}$ & occipital & single & single & $<1$ \\
\hline & 30 & $\mathrm{~F}$ & IVH & thalamus & multiple & single & $<1$ \\
\hline & 30 & $\mathrm{~F}$ & IVH & frontal & single & single & $<1$ \\
\hline & 43 & M & IVH & internal capsule & single & unreported & $<1$ \\
\hline & 52 & $\mathrm{~F}$ & ICH/IVH & central white matter & multiple & single & 1.5 \\
\hline & 13 & M & ICH/IVH & thalamus & multiple & single & $<1$ \\
\hline & 51 & $\mathrm{~F}$ & IVH & temporal & multiple & single & 1.5 \\
\hline & 52 & $\mathrm{~F}$ & $\mathrm{ICH}$ & cerebellum & multiple & single & $<1$ \\
\hline & 19 & $\mathrm{~F}$ & $\mathrm{ICH}$ & frontal & multiple & single & $<1$ \\
\hline & 48 & M & $\mathrm{ICH}$ & suprasellar & unreported & single & 1.5 \\
\hline & 10 & $\mathrm{~F}$ & SAH & frontal & single & single & $<1$ \\
\hline & 42 & $\mathrm{~F}$ & IVH & thalamus & multiple & single & $<1$ \\
\hline \multirow[t]{3}{*}{ Lee [26], 2002} & 36 & M & $\mathrm{ICH}$ & basal ganglia & multiple & single & $<3$ \\
\hline & 28 & $\mathrm{~F}$ & $\mathrm{ICH}$ & occipital & single & single & $<3$ \\
\hline & 55 & M & $\mathrm{ICH} / \mathrm{IVH}$ & basal ganglia & multiple & single & $<3$ \\
\hline Cloft [27], 2002 & 20 & M & $\mathrm{ICH}$ & cerebellum & single & unreported & 1 \\
\hline Panciani [28], 2008 & 65 & M & $\mathrm{ICH}$ & cerebellum & multiple & multiple & 1.5 \\
\hline
\end{tabular}




\section{Discussion}

The natural history of BAVM has been well described in a meta-analysis done by Gross and $\mathrm{Du}[29]$. In their analysis, the overall annual hemorrhage rate for BAVM was reported to be $3.0 \%$, with a low risk of $2.2 \%$ for unruptured AVM and a high risk of $4.5 \%$ for ruptured AVM. Ondra et al. [30] reported an annual re-bleeding rate of 4.0\%. Yamada et al. [31] demonstrated an annual rate of bleeding after initial hemorrhage of $6.8 \%$, with the highest rate of $15.4 \%$ in the first year, $5.32 \%$ in the subsequent 4 years, and $1.72 \%$ after 5 years. Patients presenting with seizures and other neurological deficits had a lower risk of hemorrhage [31]. Angiographic features associated with an increased risk of hemorrhage include a large nidus size, a deep location of the AVM, deep venous drainage, and associated aneurysm [32].

Our review of the literature regarding spontaneous BAVM thrombosis highlights many of the same clinical and angiographic characteristics seen in this case. The presence of single arterial feeders or venous drainage, a small (i.e., $<3 \mathrm{~cm}$ ) nidus size, and mass effect caused by ICH were common in previous reports, all of which were found in our case. The most common of the above-mentioned characteristics is the presence of a single draining vein, which was reported in $82.0 \%$ of the patients. Mass effect from the hematoma may cause partial or complete occlusion of the draining vein leading to blood stasis and potential thrombosis of AVM. The presence of a hematoma and the use of oral contraceptives - both previously reported to cause hypercoagulability and thrombosis by mechanical and hormonal mechanisms - may also play a role in spontaneous thrombosis $[33,34]$.

The annual rate of bleeding can be as high as $34.4 \%$ for the patient group with the combination of hemorrhagic presentation, deep location, and deep venous drainage [35]. Our patient with BAVM presented with hemorrhage but did not have other high-risk morphological features, which suggested that definitive treatment is required but not necessarily during the same hospitalization. Therefore, despite the risk of re-bleeding, it was decided to defer treatment in the acute stage of illness. Additionally, the large size of the hematoma relative to the visualized nidus suggested that the entire lesion may not be visualized due to mass effect. Incomplete visualization of the lesion has the potential to complicate surgery, particularly due to the eloquent location of the lesion in the primary visual cortex.

\section{Conclusion}

Spontaneous thrombosis of BAVM is associated with several well-described angioarchitectural and clinical characteristics, yet it remains an extremely rare and unpredictable phenomenon. Given the significant potential morbidity of any of the available treatment modalities for BAVM, spontaneous thrombosis should be regarded as a fortuitous event that may represent the most elegant resolution to a dangerous pathology. Therefore, it is important to recognize the potential benefits of early conservative management, particularly in patients with low-risk angiographic features.

\section{Acknowledgments}

The authors wish to thank Andrew J. Gienapp for technical and copy editing, the preparation of the manuscript and figures for publishing, and publication assistance with this paper. 


\begin{tabular}{l|l}
\hline \multicolumn{2}{l}{ Intervent Neurol 2014;3:122-128 } \\
\hline DOI: 10.1159/000381035 & $\begin{array}{l}\text { C 2015 S. Karger AG, Basel } \\
\text { www.karger.com/ine }\end{array}$ \\
\hline
\end{tabular}

Goyal et al.: Spontaneous Thrombosis of a Ruptured Brain Arteriovenous

Malformation: The Argument for Early Conservative Management

\section{Disclosure Statement}

Dr. Goyal has no financial relationships to disclose. Dr. Elijovich has served as a consultant for Stryker Neurovascular, Microvention, and Codman Neurovascular. Dr. Hoit has served as a consultant for Covidien.

\section{References}

1 Al-Shahi R, Warlow C: A systematic review of the frequency and prognosis of arteriovenous malformations of the brain in adults. Brain 2001;124:1900-1926.

2 Garcin B, Houdart E, Porcher R, Manchon E, Saint-Maurice JP, Bresson D, et al: Epileptic seizures at initial presentation in patients with brain arteriovenous malformation. Neurology 2012;78:626-631.

3 Spetzler RF, Martin NA: A proposed grading system for arteriovenous malformations. J Neurosurg 1986;65: 476-483.

4 Abdulrauf SI, Malik GM, Awad IA: Spontaneous angiographic obliteration of cerebral arteriovenous malformations. Neurosurgery 1999;44:280-287; discussion 287-288.

5 De Lange SA: A case of spontaneous thrombosis of a cerebral arteriovenous aneurysm (in Dutch). Ned Tijdschr Geneeskd 1955;99:944-946.

6 Kushner J, Alexander E Jr: Partial spontaneous regressive arteriovenous malformation; case report with angiographic evidence. J Neurosurg 1970;32:360-366.

7 Conforti P: Spontaneous disappearance of cerebral arteriovenous angioma. Case report. J Neurosurg 1971;34: 432-434

8 Eisenman JI, Alekoumbides A, Pribram H: Spontaneous thrombosis of vascular malformations of the brain Acta Radiol Diagn 1972;13:77-85.

9 Levine J, Misko JC, Seres JL, Snodgrass RG: Spontaneous angiographic disappearance of a cerebral arteriovenous malformation. Third reported case. Arch Neurol 1973;28:195-196.

10 Heeres JG, Hekster RE, Thomeer RA: Spontaneous thrombosis of arteriovenous malformation in cerebral vessels, 10 years after manifestation of lesion (in Dutch). Ned Tijdschr Geneeskd 1976;120:57-61.

11 Sasaki U, Itagaki T, Shimizu H, Takahashi M: Almost complete regression of cerebral arteriovenous malformation - report of a case (author's transl) (in Japanese). No Shinkei Geka 1976;4:175-181.

12 Miyazaki M, Shima T, Yokoyama N, Kuwabara S, Kuwabara S, Sasaki U, et al: Spontaneous, and postirradiation complete regression of arteriovenous malformations (AVM) of the brain proved by angiography (author's transl) (in Japanese). No Shinkei Geka 1978;6:195-203.

13 Sartor K: Spontaneous closure of cerebral arteriovenous malformation demonstrated by angiography and computed tomography. Neuroradiology 1978;15:95-98.

14 Nukui H, Miyagi O, Tamada J, Mitsuka S, Kawafuchi J: Long-term follow-up study by cerebral angiography in cases with arteriovenous malformation of the brain. With special reference to spontaneous disappearance of arteriovenous malformation in cerebral angiography (author's transl) (in Japanese). Neurol Med Chir (Tokyo) 1982;22:125-132.

15 Omojola MF, Fox AJ, Vinuela FV, Drake CG: Spontaneous regression of intracranial arteriovenous malformations. Report of three cases. J Neurosurg 1982;57:818-822.

16 Wakai S, Chen CH, Wu KY, Chiu CW: Spontaneous regression of a cerebral arteriovenous malformation. Report of a case and review of the literature. Arch Neurol 1983;40:377-380.

17 Pasqualin A, Vivenza C, Rosta L, Scienza R, Da Pian R, Colangeli M: Spontaneous disappearance of intracranial arterio-venous malformations. Acta Neurochir (Wien) 1985;76:50-57.

18 Takano S, Nose T, Maki Y, Shinohara A, Kukita C: Spontaneous occlusion of a cerebral arteriovenous malformation - report of a case (in Japanese). No Shinkei Geka 1987;15:991-996.

19 Gibb PA, Gullan RW, Sandhu N: Spontaneous angiographic disappearance of an intracranial arteriovenous malformation. Br J Neurosurg 1988;2:529-533.

20 Minakawa T, Tanaka R, Koike T, Takeuchi S, Sasaki O: Angiographic follow-up study of cerebral arteriovenous malformations with reference to their enlargement and regression. Neurosurgery 1989;24:68-74.

21 Salpietro FM, Cipri S, Tomasello F, Conforti P: Late onset of a large cavernous aneurysm after spontaneous disappearance of cerebral arteriovenous malformation. Case report. J Neurosurg Sci 1989;33:211-214.

22 Barker CS, Anslow PL: Spontaneous thrombosis of a cerebral arteriovenous malformation. Clin Radiol 1990; 42:130-132.

23 Ezura M, Kagawa S: Spontaneous disappearance of a huge cerebral arteriovenous malformation: case report. Neurosurgery 1992;30:595-599.

24 Mizutani T, Tanaka H, Aruga T: Total recanalization of a spontaneously thrombosed arteriovenous malformation. Case report. J Neurosurg 1995;82:506-508.

25 Patel MC, Hodgson TJ, Kemeny AA, Forster DM: Spontaneous obliteration of pial arteriovenous malformations: a review of 27 cases. AJNR Am J Neuroradiol 2001;22:531-536.

26 Lee SK, Vilela P, Willinsky R, TerBrugge KG: Spontaneous regression of cerebral arteriovenous malformations: clinical and angiographic analysis with review of the literature. Neuroradiology 2002;44:11-16. 
27 Cloft HJ: Spontaneous regression of cerebral arteriovenous malformation in hereditary hemorrhagic telangiectasia. AJNR Am J Neuroradiol 2002;23:1049-1050.

28 Panciani PP, Fontanella M, Carlino C, Bergui M, Ducati A: Progressive spontaneous occlusion of a cerebellar AVM: pathogenetic hypothesis and review of literature. Clin Neurol Neurosurg 2008;110:502-510.

29 Gross BA, Du R: Natural history of cerebral arteriovenous malformations: a meta-analysis. J Neurosurg 2013; 118:437-443.

30 Ondra SL, Troupp H, George ED, Schwab K: The natural history of symptomatic arteriovenous malformations of the brain: a 24-year follow-up assessment. J Neurosurg 1990;73:387-391.

31 Yamada S, Takagi Y, Nozaki K, Kikuta K, Hashimoto N: Risk factors for subsequent hemorrhage in patients with cerebral arteriovenous malformations. J Neurosurg 2007;107:965-972.

32 Lv X, Wu Z, Jiang C, Yang X, Li Y, Sun Y, et al: Angioarchitectural characteristics of brain arteriovenous malformations with and without hemorrhage. World Neurosurg 2011;76:95-99.

33 Mabe H, Furuse M: Spontaneous disappearance of a cerebral arteriovenous malformation in infancy. Case report. J Neurosurg 1977;46:811-815.

34 Lidegaard 0, Kreiner S: Cerebral thrombosis and oral contraceptives. A case-control study. Contraception 1998;57:303-314.

35 Stapf C, Mast H, Sciacca RR, Choi JH, Khaw AV, Connolly ES, et al: Predictors of hemorrhage in patients with untreated brain arteriovenous malformation. Neurology 2006;66:1350-1355. 